\title{
The mathematical model of rainwater catchment in Wroclaw
}

\author{
Monika Nowakowska ${ }^{1, *}$ \\ ${ }^{1}$ Faculty of Environmental Engineering, Wroclaw University of Science and Technology, Department \\ of Water and Sewage, Wybrzeże Wyspiańskiego 27, 50-370 Wroclaw, Poland
}

\begin{abstract}
On the basis of field studies of canalized storm water catchment of Gaj and Tarnogaj estate in Wrocław the rules of construction of hydrodynamic models in SWMM program were presented. The process of identification of hydrological and hydraulic parameters of the model, in the course of its calibration and validation were presented. To assess the quality of model the rates and statistical criteria were proposed to compare the results of stream simulation and volume of runoff of effective precipitation with the results of the measurements.
\end{abstract}

\section{Introduction}

Escalating in recent years extreme weather phenomena such as incidental or prolonged rainfall and associated with them flooding cause significant economic losses. In the existing, modernized or newly designed sewage systems the verification of hydraulic capacity of networks and objects is now recommended, including overflows from channels towards hydrodynamic modeling at different scenarios of precipitation load.

Modeling of systems reliability recommended by standard PN-EN 752:2008 is rarely applied in Poland [1] - with regard to the verification of the frequency of overflow from channels and even required by law according to the regulation of the Minister of the environment from 2014 [2] - with regard to the verification of the frequency of storm water overflows. This is mainly the result of the lack of sufficient basis of modeling methods as well as appropriate output databases with regard to monitoring of precipitation and overflows in sewage systems [3]. For instance, the level of integration of sub-catchment area is as yet intuitively. Usually channels with diameter smaller than $0.5 \mathrm{~m}$ are omitted and the width of the hydraulic sub-catchment is designated from several different formulas. In calibration and validation of hydrodynamic models data from the short period of observation are taken into consideration (i.e. few months) and the assessment of the quality of hydrodynamic models is based on various statistical indicators for comparison of the simulation results of sewage with the measurement results.

Based on the example of local data regarding the precipitation and streams of storm water in Wrocław the principles of the construction of mathematical model for drainage the area in SWMM program were presented.

\footnotetext{
* Corresponding author: monika.nowakowska@pwr.edu.pl
} 


\section{Material and methods of studies}

For field research the canalized catchment of Gaj and Tarnogaj estate in Wrocław were selected, with the area $F=104$ hectares - giving runoff to indoor drainage collector KD1 (with diameters from $0.3 \mathrm{~m}$ to $1.4 \mathrm{~m}$ ). From the total area of estates, the dimpled areas were excluded, including allotments from which the sewage runoff of precipitation taking place into the ditches. The total length of the inventoried channels was $17731 \mathrm{~m}$ and the number of drains 509. This gives an average spacing of drains $34.8 \mathrm{~m}$, which can be considered as representative for the cities.

On the stage of identification, as a minimum diameter of channels taking $d_{\min } \geq 0.3 \mathrm{~m}$, 75 catchment area were discharged. In sub-catchments sealed areas were distinguished - not having retention $F_{d}$ (roofs), sealed areas-with retention $F_{a}$ (asphalt road) and $F_{k . b}$ (carriageways with concrete block or cobblestone) and areas not sealed ("green" areas) with retention $F_{n u}$. Then degrees of sealed area were calculated in each sub-catchments: total sealing degree: $\% F_{u}=F_{u} / F_{i}$, degree of area sealing without retention: $\% F_{u b r}=F_{u b r} / F_{u}$ and degree of area sealing with retention: $\% F_{u z r}=F_{u z r} / F_{u}$. Slope of area $\left(i_{p}\right)$ in the sub-catchments were adopted as weighted average-from the area of the terrain, streets, squares and roofs (tab. 1).

Table 1. Summary of characteristic area and slope of sub-catchments.

\begin{tabular}{|c|c|c|c|c|c|c|c|c|c|c|c|c|}
\hline \multirow{3}{*}{ Area no. } & \multirow{3}{*}{$\begin{array}{l}\text { Mark of } \\
\text { catchment } \\
\text { area }\end{array}$} & \multirow{3}{*}{$\begin{array}{c}\text { Node } \\
\text { no. }\end{array}$} & \multirow{2}{*}{$\begin{array}{c}\text { Catch } \\
\text { ment } \\
\text { area } \\
F_{i}\end{array}$} & \multicolumn{4}{|c|}{ Sealed areas $F_{u}$} & \multirow{2}{*}{$\begin{array}{c}\text { Areas } \\
\text { not } \\
\text { sealed } \\
F_{n u}\end{array}$} & \multirow[b]{2}{*}{$\% F_{u}$} & \multirow[b]{2}{*}{$\% F_{u b r}$} & \multirow[b]{2}{*}{$\% F_{u z r}$} & \multirow[b]{2}{*}{$i_{p}$} \\
\hline & & & & $F_{d}$ & $F_{a}$ & $F_{b}$ & $\Sigma F_{u}$ & & & & & \\
\hline & & & \multicolumn{6}{|c|}{ ha } & \multicolumn{3}{|c|}{$\%$} & $\%$ \\
\hline 1 & $\mathrm{P} 1$ & 18 & 0.9019 & 0.1175 & 0.1926 & 0.3315 & 0.6416 & 0.2603 & 71.1 & 183 & 81.7 & 1.20 \\
\hline 4 & P4 & 45 & 1.3590 & 0.6212 & 0.0000 & 0.7378 & 13590 & 0.0000 & 100.0 & 45.7 & 54.3 & 1.18 \\
\hline 9 & P9 & 65 & 0.2985 & 0.0000 & 0.1178 & 0.0407 & 0.1585 & 0.1400 & 53.1 & 0.0 & 100.0 & 1.11 \\
\hline 12 & P11 & 73 & 2.4492 & 0.6616 & 13501 & 0.0858 & 2.0974 & 03517 & 85.6 & 31.5 & 68.5 & 121 \\
\hline 16 & P14.1 & 119 & 0.2220 & 0.0000 & 0.0929 & 0.0260 & 0.1189 & 0.1031 & 53.6 & 0.0 & 100.0 & 1.12 \\
\hline 20 & P16.1 & 99 & 3.4074 & 12146 & 02309 & 1.5695 & 3.0150 & 03924 & 88.5 & 403 & 59.7 & 1.10 \\
\hline 21 & $\mathrm{P} 17$ & 121 & 0.5730 & 0.0000 & 0.1896 & 0.1891 & 03787 & 0.1943 & 66.1 & 0.0 & 100.0 & 0.17 \\
\hline 31 & P21.1 & 142 & 1.0254 & 0.0000 & 0.8203 & 0.1230 & 0.9434 & 0.0820 & 92.0 & 0.0 & 100.0 & 0.33 \\
\hline 32 & $\mathrm{P} 22$ & 170 & 22621 & 0.1900 & 0.0414 & 0.1015 & 03330 & 1.9291 & 14.7 & 57.1 & 42.9 & 0.22 \\
\hline 33 & $\mathrm{P} 23$ & 170 & 1.8855 & 0.0000 & 02625 & 0.3150 & 0.5775 & 1.3080 & 30.6 & 0.0 & 100.0 & 0.68 \\
\hline 34 & $\mathrm{P}$ & 182 & 3.4543 & 0.4098 & 0.0609 & 0.0895 & 0.5602 & 2.8941 & 162 & 732 & 26.8 & 0.18 \\
\hline 37 & $\mathrm{P}$ & 242 & 0.6718 & 0.0000 & 0.1671 & 0.1537 & 03208 & 03510 & 47.8 & 0.0 & 100.0 & 1.01 \\
\hline 43 & $\mathrm{P} 282$ & 2380 & 1.3525 & 0.3852 & 0.0000 & 0.0553 & 0.4405 & 0.9120 & 32.6 & 87.4 & 12.6 & 0.72 \\
\hline 56 & $\mathrm{P} 38$ & 322 & 0.7092 & 0.0263 & 0.4255 & 0.2128 & 0.6646 & 0.0446 & 93.7 & 4.0 & 96.0 & 1.81 \\
\hline 68 & P46 & 382 & 5.3379 & 1.3345 & 0.4404 & 0.8195 & 25944 & 2.7435 & 48.6 & 51.4 & 48.6 & 0.55 \\
\hline 71 & P48 & 454 & 0.5189 & 0.0000 & 0.1920 & 0.0327 & 02247 & 0.2942 & 43.3 & 0.0 & 100.0 & 0.92 \\
\hline 75 & P51 & 505 & 1.0265 & 0.1721 & 02344 & 0.1875 & 0.5940 & 0.4325 & 57.9 & 29.0 & 71.0 & 1.20 \\
\hline \multicolumn{3}{|c|}{ SUM/AVERAGE } & 103.98 & 23.66 & 15.41 & 22.44 & 61.50 & 42.47 & 59.2 & 38.5 & 61.5 & 0.93 \\
\hline \multicolumn{3}{|c|}{$\mathrm{MIN}$} & 0.2220 & 0.0000 & 0.0000 & 0.0260 & 0.1189 & 0.0000 & 14.7 & 0.0 & 12.6 & 0.17 \\
\hline \multicolumn{3}{|c|}{ MAX } & 5.3379 & 1.3345 & 13501 & 1.5695 & 3.0150 & 2.8941 & 100 & 87.4 & 100 & 1.81 \\
\hline
\end{tabular}

Individual sub-catchments were organized into 75 network nodes, to which rainwater is drained (fig. 1). 


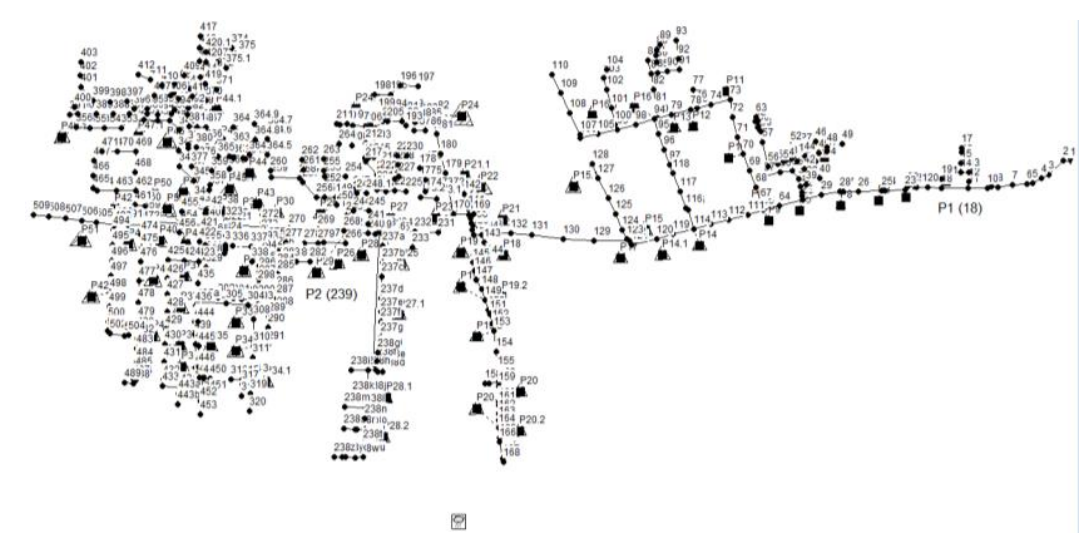

Fig. 1. The scheme of the analyzed storm water drainage in SWMM program.

As the basis to determine hydraulic width of sub-catchment $(W)$, the basic form of the formula was taken:

where:

$$
W=x \sqrt{ } F
$$

$F$ - area of storm water catchment/sub-catchment, $\mathrm{m}^{2}$.

In subject literature, the formula (1) is most commonly used with multipliers for values: $x=1.0[6-8]$ or $x=1.5$ [9-11]. In Wroclaw's conditions to render the parameter $W$ it turned out that the best value was $x=1.6$, which will be demonstrated later in this study.

To conduct simulation calculations in SWMM program it was necessary to create databases involving precipitation of rain in catchment and measurement of sewage streams in KD1 collector. For metering sewage streams two ultrasonic flow meters were used. Nivus type flow meter (P1 - fig. 1) was installed in drain no. 18 on the section of KD1 with a diameter of $1.4 \mathrm{~m}$. The second type of flow meter Teledyne (P2) was installed in the drain no. 239 , on the section KD1 with a diameter of $1.2 \mathrm{~m}$.

The rain gauge type TRwS was a device used to register rainfall in the catchment located on the southern boundary of the catchment area of Gaj and Tarnogaj estate at a distance of about $620 \mathrm{~m}$ from the center of gravity of the tested catchment (fig. 1). Registry of precipitation was conducted for a period of 2 years, from July $29^{\text {th }} 2013$ to July $19^{\text {th }} 2015$. Precipitation with duration time $t>45 \mathrm{~min}$ and height $h>10 \mathrm{~mm}$ were taken for calibration and validation of the model. Both torrential rains - those of short duration (convective K), as well as those of long-term (frontal $\mathrm{F}$ and lowland $\mathrm{N}$ ), which hyetographs have a continuous character were taken into consideration. The chosen precipitation was assigned later to their frequency of occurrence in Wrocław. As a criterion to determine the frequency of precipitation occurrence was taken the probabilistic model of maximum height in Wrocław (based on the distribution of Fisher-Tippett type III) - for $C \in[1 ; 100]$ years [12], and for precipitation occurring more frequently than once a year $(C \in[0.1 ; 1))$ a physical model was used [3]. These precipitations were detailed about episodes of time duration equal to time of flow of sewage in collector KD1 to the intersection of flowmeter $\mathrm{P} 1(t \approx 45 \mathrm{~min})$ and $\mathrm{P} 2(t \approx 15 \mathrm{~min})$. The parameters of 8 precipitation selected for calibration and validation of the model are given in table 2 . 
Table 2. The parameters of precipitation for calibration (no. 1-5) and validation of model (no. 6-8).

\begin{tabular}{|c|c|c|c|c|c|c|c|c|c|}
\hline \multirow{2}{*}{$\begin{array}{c}\text { Number, type and } \\
\text { date of } \\
\text { precipitation }\end{array}$} & \multicolumn{2}{|c|}{ Time } & \multirow{2}{*}{$\begin{array}{c}\text { Time } \\
t \\
\min \end{array}$} & \multirow{2}{*}{$\begin{array}{l}\Sigma h \\
\mathbf{m m}\end{array}$} & \multirow{2}{*}{$\begin{array}{c}C \\
\text { year } \\
\mathbf{s}\end{array}$} & \multirow{2}{*}{$\begin{array}{l}h_{45} \\
\mathrm{~mm}\end{array}$} & \multirow{2}{*}{$\begin{array}{c}C_{45} \\
\text { years }\end{array}$} & \multirow{2}{*}{$\begin{array}{c}h_{15} \\
\mathrm{~mm}\end{array}$} & \multirow{2}{*}{$\begin{array}{c}C_{15} \\
\text { years }\end{array}$} \\
\hline & fro & to & & & & & & & \\
\hline 1. F 17.05.2014 & $09: 45$ & $17: 09$ & 444 & 15.1 & 0.55 & 5.6 & 0.36 & 3.0 & 0.27 \\
\hline 2. N 23- & $3: 34$ & 15:09 & 935 & 13.1 & 0.41 & 3 & .19 & 1. & 0.13 \\
\hline $3 . \mathrm{N} \mathrm{1-}$ & $15: 27$ & $13: 47$ & 1340 & 13 & 0.40 & 1. & 0 . & 1.0 & $<0.1$ \\
\hline 4.1 & $8: 01$ & $22: 54$ & 894 & 11.7 & 0.3 & 2. & .12 & 1.6 & 0. \\
\hline $5 . \mathrm{N}^{2}$ & 01:00 & 3 & 1468 & 28. & 0.75 & 2 & 0. & 1.5 & 0.11 \\
\hline 6. & 26 & $22: 12$ & 106 & 15.7 & 0.85 & 14. & 1.1 & 13.4 & 2.4 \\
\hline & $18: 37$ & $20: 12$ & 95 & 9.7 & 0.52 & 8.6 & 0.3 & 6. & 0.61 \\
\hline 8. K 19.07.2015 & $19: 57$ & $20: 39$ & 42 & 23.8 & 5.1 & 23.8 & 4.7 & 22.1 & 18.4 \\
\hline
\end{tabular}

To assess the quality of the model selected statistical measure were used for comparing the results of measurements and calculations of the outflow $(Q)$, such as $[3-5,13-15]$ :

- $\quad$ special rate of correlation $R S$ :

$$
R S=\sqrt{\sum_{i=1}^{n}\left(2 \cdot Q_{p, i} \cdot Q_{o, i}-Q_{o, i}^{2}\right) / \sum_{i=1}^{n} Q_{p, i}^{2}}
$$

- relative residual error $W B R$ :

$$
W B R=\sqrt{n \cdot\left(\sum_{i=1}^{n}\left(Q_{p, i}-Q_{o, i}\right)^{2}\right)} / \sum Q_{p, i}
$$

- $\quad$ average value error $S W S$ :

$$
S W S=\bar{Q}_{o} / \bar{Q}_{p}
$$

- relative error of maximum streams $\Delta Q_{\max }$ :

$$
\Delta Q_{\max }=\frac{Q_{\max , p}-Q_{\max , o}}{Q_{\max , p}} \cdot 100 \%
$$

Indexes " $p$ ", and " $o$ " in formulas (2-5) mean respectively measurements and calculations. The value " $n$ " corresponds to the number of extracted compartments-averaged values $Q$ in a registered hydrographic of runoff. Depending on the value of the rate, the model can be qualified for the specified category. Ranges of values of rates RS and WBR together with corresponding categories of models were listed in table 3 . For SWS rates and $\Delta Q_{\max }$ the ranges of values for the appropriate category of model were not specified. The only known limit values appropriate for situation when the model perfectly reproduces reality: $\mathrm{SWS}=1.0$ i $\Delta Q_{\max }=0$.

Table 3. Categories for the classification of the models.

\begin{tabular}{|c|c|c|}
\hline \multirow{2}{*}{ Category of model } & \multicolumn{2}{|c|}{ Rates-ranges of values } \\
\cline { 2 - 3 } & RS [-] & WBR [\%] \\
\hline Excellent & $1.00-0.99$ & $0-3$ \\
\hline Very good & $0.99-0.95$ & $3-6$ \\
\hline Good & $0.95-0.90$ & $6-10$ \\
\hline Average & $0.90-0.85$ & $10-25$ \\
\hline Dissatisfying & $<0.85$ & $>25$ \\
\hline
\end{tabular}




\section{Calibration of model}

Calibration of hydrodynamic model was based on determining the values of parameters:

- hydraulic - roughness rate of channels ( $n$ - to Manning formula) and roughness rate of sealed $\left(n_{p u}\right)$ and unsealed $\left(n_{p n u}\right)$ catchment areas,

- hydrological - the height of retention on sealed $\left(h_{p u}\right)$ and unsealed $\left(h_{p n u}\right)$ catchment areas. Hydrogeological parameters of model (infiltration) were estimated by model of expert. As a result of the simulation calculations in SWMM program for 5 long-term precipitation calibration (type $\mathrm{F}$ and $\mathrm{N}$-table 2) the empirical parameters of the model were determined. In table 4 the literature (output) and resulting values of the parameters of model of the tested drainage system were listed.

Table 4. The value of the calibration parameters of the model of tested drainage system.

\begin{tabular}{|c|c|c|c|c|c|c|c|c|c|c|}
\hline Parameter & 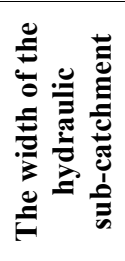 & 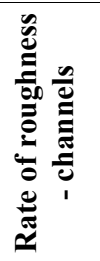 & 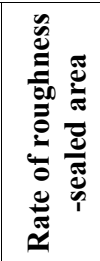 & 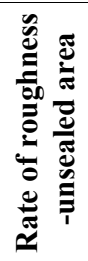 & 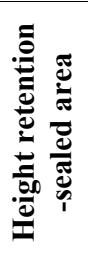 & 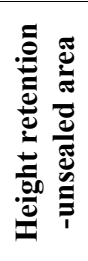 & 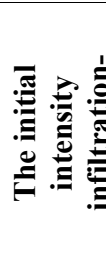 & 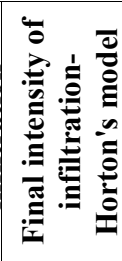 & 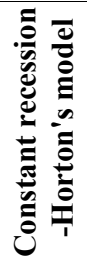 & 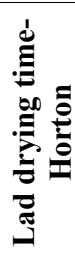 \\
\hline Symbol & $W$ & $n$ & $n_{p u}$ & $n_{p n u}$ & $h_{p u}$ & $h_{p n u}$ & $I_{\text {in } 0}$ & $I_{\text {ink }}$ & $r$ & $T_{s}$ \\
\hline Unit & $\mathrm{m}$ & $\mathrm{s} / \mathrm{m}^{1 / 3}$ & $\mathrm{~s} / \mathrm{m}^{1 / 3}$ & $\mathrm{~s} / \mathrm{m}^{1 / 3}$ & $\mathrm{~mm}$ & $\mathrm{~mm}$ & $\mathrm{~mm} / \mathrm{h}$ & $\mathrm{mm} / \mathrm{h}$ & $\mathrm{h}^{-1}$ & $\mathrm{~d}$ \\
\hline $\begin{array}{l}\text { Literature data } \\
\text { for calibration }\end{array}$ & $\begin{array}{l}\text { various } \\
\text { formulas }\end{array}$ & $\begin{array}{c}0.013- \\
0.020\end{array}$ & $\begin{array}{c}0.011- \\
0.050\end{array}$ & $\begin{array}{c}0.1- \\
0.8\end{array}$ & $\begin{array}{l}1.3- \\
2.5\end{array}$ & $\begin{array}{c}2.5- \\
7.5\end{array}$ & $8-254$ & $0.2-20$ & $2-7$ & $2-14$ \\
\hline $\begin{array}{l}\text { Results of model's } \\
\text { calibration in } \\
\text { SWMM program }\end{array}$ & $1.6 \sqrt{ } F$ & 0.020 & 0.020 & 0.3 & 2.0 & 5.0 & 90 & 10 & 4 & 7 \\
\hline
\end{tabular}

About the optimum values of parameters of the model proclaim the achieved values of indicators: RS, WBR, SWS and $\Delta Q_{\max }$, adopted as the statistical criteria to evaluate the quality of the model. However, the most important was the achievement of the compliance of simulated values with the values measured with respect to the balance of the volume of runoff $(V)$, as shown in Chapter 4 . In table 5 the final results of the calculation accuracy of the model for 5 precipitation calibrations and three forms of formula for the parameter $W$. The best results were achieved for $W 3$. On the basis of the value of the indicators RS and WBR the calibrated model was assessed on the border of grades good and very good (according to the criteria from the table 3).

Figure 2 shows, for example, a histogram of precipitation and hydrographs of sewage streams in collector KD1 (intersection $\mathrm{P} 1$ ) for the latest lowland precipitation $(\mathrm{N})$ from October $22^{\text {nd }}$ to $23^{\text {rd }} 2014$. 
Table 5. The results of the calculations of the calibration model.

\begin{tabular}{|c|c|c|c|c|c|c|c|c|c|c|c|}
\hline \multirow{2}{*}{ Formula } & \multirow{2}{*}{$\begin{array}{c}\text { Precipitation } \\
\text { data } \\
\text { FLOWMETER }\end{array}$} & \multicolumn{2}{|c|}{17.05 .2014} & \multicolumn{2}{|c|}{ 23-24.07.2014 } & \multicolumn{2}{|c|}{$1-2.09 .2014$} & \multicolumn{2}{|c|}{11.09 .2014} & \multicolumn{2}{|c|}{$22-23.10 .2014$} \\
\hline & & $\mathrm{P} 1$ & $\mathrm{P} 2$ & $\mathrm{P} 1$ & P2 & P1 & P2 & P1 & P2 & P1 & P2 \\
\hline \multirow{4}{*}{$W 1=\sqrt{ } F$} & RS [-] & 0.977 & 0.930 & 0.977 & 0.970 & 0.967 & 0.973 & 0.958 & 0.938 & 0.980 & 0.976 \\
\hline & WBR [\%] & 4.0 & 73 & 5.9 & 72 & 6.0 & 5.9 & 6.8 & 9.8 & 4.7 & 52 \\
\hline & SWS [-] & 0.940 & 1.030 & 0.989 & 1.113 & 0.993 & 1.011 & 1.057 & 1.147 & 1.018 & 1.100 \\
\hline & $\Delta Q_{\max }[\%]$ & 149 & 20.8 & 0.9 & -6.4 & 9.8 & 09 & 182 & 13.7 & 16.5 & 12.3 \\
\hline \multirow{4}{*}{$W 2=1.5 \sqrt{ } F$} & RS [-] & 0.985 & 0.949 & 0.983 & 0.970 & 0.971 & 0.976 & 0.968 & 0.954 & 0.982 & 0.978 \\
\hline & WBR [\%] & 32 & 62 & 5.1 & 7.2 & 5.6 & 5.4 & 6.0 & 8.5 & 4.5 & 5.0 \\
\hline & SWS [-] & 0.943 & 1.032 & 0.993 & 1.117 & 0.997 & 1.014 & 1.061 & 1.150 & 1.019 & 1.099 \\
\hline & $\Delta \mathrm{Q}_{\max }[\%]$ & 11.5 & 14.5 & -0.4 & -10.6 & 69 & -6.3 & 14.5 & 7.1 & 16.1 & 11.8 \\
\hline \multirow{4}{*}{$W 3=1.6 \sqrt{ } F$} & RS [-] & 0.986 & 0.951 & 0.983 & 0.970 & 0.972 & 0.977 & 0.969 & 0.956 & 0.982 & 0.979 \\
\hline & WBR [\%] & 3.1 & 6.1 & 5.0 & 7.3 & 5.6 & 5.4 & 5.9 & 8.3 & 4.4 & 5.0 \\
\hline & SWS [-] & 0.943 & 1.033 & 0.994 & 1.117 & 0.997 & 1.014 & 1.061 & 1.151 & 1.020 & 1.099 \\
\hline & $\Delta \mathrm{Q}_{\max }[\%]$ & 11.0 & 13.6 & -0.6 & -11.2 & 6.5 & -7.4 & 14.0 & 6.3 & 16.0 & 11.7 \\
\hline
\end{tabular}

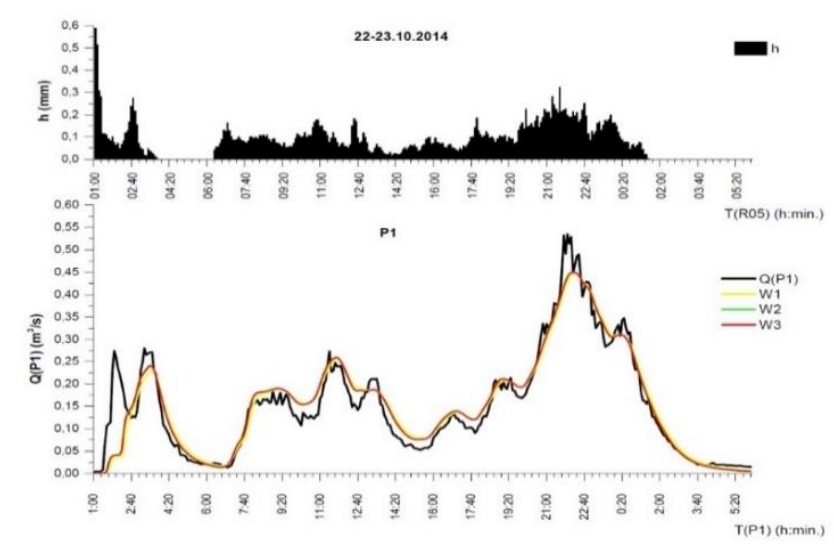

Fig. 2. A histogram of precipitation and hydrographs of flow into the collector KD1 (P1) for the latest lowland precipitation from October $22^{\text {nd }}$ to $23^{\text {rd }} 2014$.

\section{Validation of model}

Validation of tested hydrodynamic model of drainage system consists in checking the accuracy of the already calibrated model on the 3 short-lived intense convective precipitation (K-tab. 2) with criterion of compatibility of the balance volume of runoff $(V)$. Figure 3 shows an example of histogram of convective precipitation from July $19^{\text {th }} 2015$ and hydrographs of drainage (measured and simulated) in collector KD1 in the intersection of flowmeter P1. 


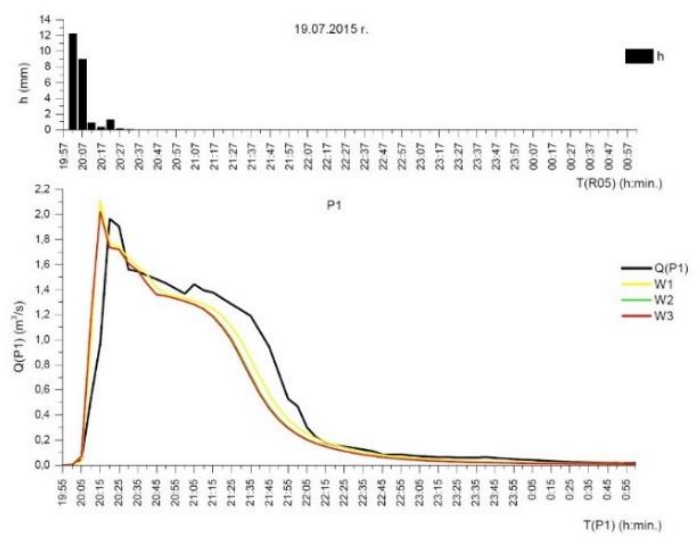

Fig. 3. A histogram of precipitation and hydrographs of flow into the collector KD1 (P1) - for convective precipitation from July $19^{\text {th }} 2015$.

Table 6 presents the results of a calculation parameter $W$ for 3 validated precipitation (K). Accuracy of mapping of tested phenomena precipitation-outflow through the created model of canalized storm water catchment were presented cumulatively for 8 precipitation, i.e. 5 from calibration and 3 from validation. Figure 4 shows the correspondence with the volume balance of runoff $(V)$.

Table 6. The results of the validation calculations.

\begin{tabular}{|c|c|c|c|c|c|}
\hline \multirow{3}{*}{ Formula } & $\begin{array}{c}\text { Precipitation } \\
\text { data } \\
\text { /flowmeter }\end{array}$ & $\mathbf{2 9 . 0 7 . 2 0 1 3}$ & \multicolumn{1}{|c|}{$\mathbf{1 7 . 1 0 . 2 0 1 4}$} & $\mathbf{1 9 . 0 7 . 2 0 1 5}$ \\
\cline { 2 - 6 } & RS [-] & 0.988 & 0.994 & 0.992 & 0.970 \\
\hline \multirow{5}{*}{$W 1=\sqrt{ } F$} & WBR [\%] & 2.2 & 1.1 & 1.6 & 3.0 \\
\cline { 2 - 6 } & SWS [-] & 1.122 & 1.070 & 1.089 & 0.932 \\
\cline { 2 - 6 } & $\Delta$ Qmax [\%] & -3.0 & 3.3 & 5.4 & -7.2 \\
\hline \multirow{4}{*}{$W 2=1.5 \sqrt{ } \mathrm{F}$} & RS [-] & 0.978 & 0.996 & 0.995 & 0.962 \\
\cline { 2 - 6 } & WBR [\%] & 3.0 & 0.9 & 1.2 & 3.3 \\
\cline { 2 - 6 } & SWS [-] & 1.098 & 1.083 & 1.102 & 0.883 \\
\cline { 2 - 6 } & $\Delta$ Qmax [\%] & -7.7 & -0.3 & -0.8 & -3.2 \\
\hline \multirow{5}{*}{$W 3=1.6 \sqrt{ } F$} & RS [-] & 0.978 & 0.996 & 0.995 & 0.961 \\
\cline { 2 - 6 } & WBR [\%] & 3.0 & 1.0 & 1.3 & 3.4 \\
\cline { 2 - 6 } & SWS [-] & 1.090 & 1.084 & 1.103 & 0.876 \\
\cline { 2 - 6 } & $\Delta$ Qmax [\%] & -5.5 & -1.0 & -1.7 & -2.8 \\
\hline
\end{tabular}




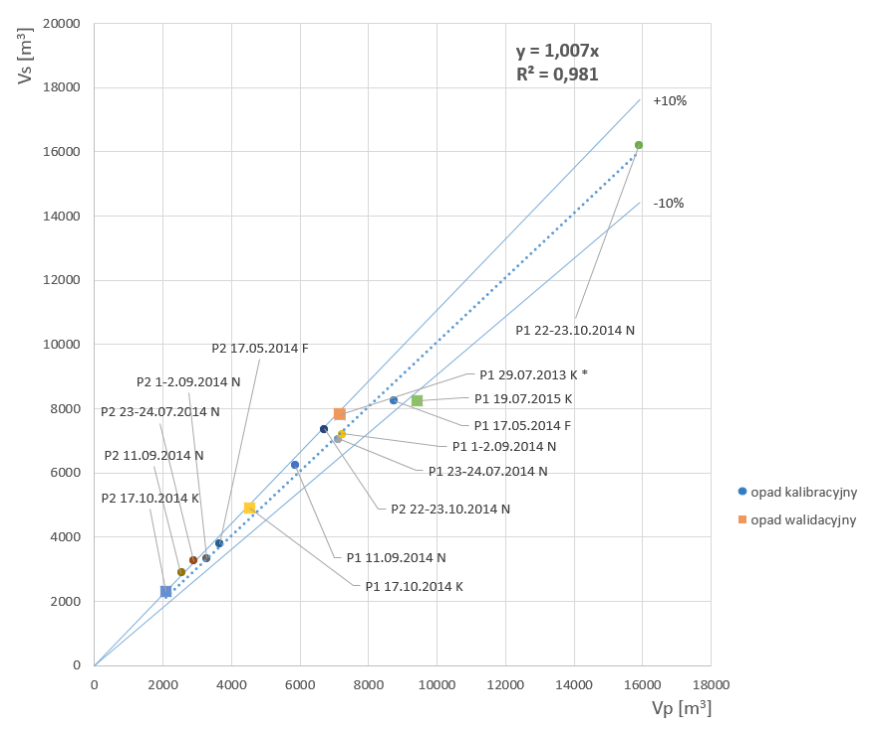

Fig. 4. The volume balance of runoff for precipitation from calibration and validation model.

Figure 4 shows that for 8 precipitations (from calibration and validation model) the volume of runoff describes the simple equation $V_{s} \approx V_{p}$ where $\mathrm{R}^{2}=0.981$. This means high compliance of the simulated $(S)$ and measured $(P)$ volumes of precipitations runoff 14 results of measurements and simulation is in the range accuracy $\pm 10 \%$.

\section{Summary and conclusions}

In this paper the rules for the mathematical model of the drainage system in Wrocław area in SWMM program were showed. Selected results of studies about identification, calibration and validation of empirical parameters of the model along with the verification of formulas to determine the width of the hydraulic $(W)$ sub-catchment were presented. Discussed results of this study have in methodical part universal character and are used to build models of other hydrodynamic urban catchment. Identification of the major parameters of empirical models $\left(n, n_{p u}, n_{p n u}, h_{p u}\right.$ and $h_{p n u}$ ) should be carried out in the course of their calibration on long-term precipitation (frontal and lowland) and in the course of the validation of the models on the intense precipitation (convection) with the compatibility criterion of the balance volume of runoff $(V)$. To assess the quality of models the optional statistical indicators can be used (RS, WBR, SWS and $\Delta Q_{\max }$ ) describing the fitting accuracy of simulated and measured values of waste water streams.

The work was realized within the allocation No. 0401/0069/16 awarded for Faculty of Environmental Engineering Wroclaw University of Science and Technology by Ministry of Science and Higher Education in years 2016-2017.

\section{References}

1. PN-EN 752:2008, Drain and sewer systems outside buildings (PKN, Warszawa, 2008)

2. Rozporządzenie Ministra Środowiska z dnia 18 listopada 2014 r., Dz. U. RP z dnia 16 grudnia 2014 r., poz. 1800 
3. A. Kotowski, Basics of safe dimensioning of drainage areas (Seidel-Przywecki, Wroclaw, 2015)

4. M. Nowakowska, Identification of hydrological and hydraulic parameters of urban catchment area in SWMM hydrodynamic modeling (Oficyna Wydawnicza Politechniki Wrocławskiej, Wroclaw, 2016)

5. M. Nowakowska, A. Kotowski, Methodology and rules for modelling drainage of urban areas (Oficyna Wydawnicza Politechniki Wrocławskiej, Wroclaw, 2017)

6. M. Mrowiec, Effective dimensioning and dynamic regulation of sewerage retention tanks (PCz., Czestochowa, 2009)

7. M. Skotnicki, M. Sowiński, Verification of the method for determining the hydraulic width of a sub-catchment on the example of a selected urban catchment (PW., Warszawa, 2009)

8. D. Słyś, A. Stec, Environ. Prot. Eng. 38, 99-112 (2012)

9. M. Zawilski, G. Sakson, Gaz, Woda Tech. Sanit. 11, 32-36 (2010)

10. M. Zawilski, G. Sakson, Gaz, Woda Tech. Sanit. 9, 321-323 (2011)

11. M. Zawilski, Gaz, Woda Tech. Sanit. 6, 28-32 (2010)

12. A. Kotowski, B. Kaźmierczak, A. Dancewicz, Modeling precipitation for sewage dimensioning (PAN, 68, Warszawa, 2010)

13. I.R.A. Green, D. Stephenson, Hydrologie Sciences J. 31, 395-411 (1986)

14. W. James, Rules for responsible modeling (CHI Publications, Guelph, 2003)

15. M. Ozga-Zielińska, J. Brzeziński, Practical hydrology (PWN, Warszawa, 1997)

16. ASCE, Design \& Construction of Urban Stormwater Management Systems (New York 1992)

17. U.K. Maheepala, A.K. Takyi, B.J.C. Perera, J. Hydrology 245, 32-47 (2001)

18. R. Mccuen, P. Johnson, R. Ragan, Hydrology (Federal Highway Administration, Washington, 1996)

19. PIT R., Infiltration Through Disturbed Urban Soils and Compost-Amended Soil Effects on Runoff Quality and Quantity. United States Environmental Protection Agency, Washington (1999)

20. L.A. Rossman, Storm Water Management Model. User's Manual. United States Environmental Protection Agency, Washington (2010) 